\title{
Penerapan Metode Smart Dalam Menentukan Mata Kuliah Terfavorit Pada Kampus Merdeka Di STIKOM Tunas Bangsa
}

\author{
Muhammad Fachrur Rozy ${ }^{1,}$, , Irfan Sudahri Damanik², Ilham Syahputra Saragih ${ }^{3}$ \\ ${ }^{1,2,3}$ Program Studi Sistem Informasi, STIKOM Tunas Bangsa, Pematangsiantar, Indonesia \\ Email: 1," ${ }^{*} w w . r o j a k . x 8 @ g m a i l . c o m,{ }^{2}$ irfansudahridamanik@amiktunasbangsa.ac.id, \\ ${ }^{3}$ ilhamsyahputrasaragih@amiktunasbangsa.ac.id
}

\section{INFORMASI ARTIKEL}

Sejarah Artikel:

Diterima Redaksi : 00 Bulan 0000

Revisi Akhir : :00 Bulan 0000

Diterima : :00 Bulan 0000

Diterbitkan Online : 00 Bulan 0000

\section{KATA KUNCI}

Kampus Merdeka,

Algoritma SMART,

Sistem Informasi

KORESPONDENSI

E-mail: www.rojak.x8@gmail.com

\begin{abstract}
A B S S T R A A C T
Saat ini kreativitas dan inovasi menjadi kata kunci penting untuk memastikan pembangunan Indonesia yang berkelanjutan. Para mahasiswa yang saat ini belajar di Perguruan Tinggi, harus disiapkan menjadi pembelajar sejati yang terampil, lentur dan ulet. Kebijakan Merdeka Belajar - Kampus Merdeka yang diluncurkan oleh Menteri Pendidikan dan Kebudayaan merupakan kerangka untuk menyiapkan mahasiswa menjadi sarjana yang tangguh, relevan dengan kebutuhan zaman, dan siap menjadi pemimpin dengan semangat kebangsaan yang tinggi. Proses pengambilan data diperoleh dengan cara membagikan kuisioner dan observasi secara langsung.Dengan variable jumlah SKS, peluang pekerjaan, dan alasan mahasiswa dalam mengambil mata kuliah pada kampus merdeka. Hasil penelitian ini berupa mata kuliah yang akan diambil berdasarkan mata kuliah yang ada pada Kampus Merdeka di STIKOM Tunas Bangsa.
\end{abstract}

\section{PENDAHULUAN}

Perkembangan ilmu pengetahuan dan teknologi sudah sangat pesat pada masa sekarang. Hal ini telah membawa perubahan yang sangat besar pula dalam berbagai aspek kehidupan. Perubahan ekonomi, sosial, dan budaya juga terjadi dengan laju yang tinggi[1]. Dalam masa yang maju saat ini, perguruan tinggi harus merespon secara cepat dan tepat. Diperlukan perubahan pembelajaran agar bisa membekali dan menyiapkan para lulusan perguruan tinggi agar menjadi generasi yang unggul dan tidak kalah dalam persaingan yang bebas pada masa ini. Kampus Merdeka merupakan kebijakan dari Menteri Pendidikan dan Kebudayaan, yaitu Bapak Nadiem Makarim, yang bertujuan membantu mahasiswa untuk menguasai berbagai ilmu pengetahuan untuk memasuki dunia kerja. Kampus Merdeka memberikan kesempatan bagi mahasiswa untuk memilih mata kuliah yang akan mereka ambil selama 3 semester berupa 1 semeseter mengambil mata kuliah di luar program studi tetapi masih berada dalam 1 perguruan tinggi, dan 2 semester melaksankan aktivitas pembelajaran diluar perguruan tinggi. Berbagai bentuk aktivitas pembelajaran diluar perguruan tinggi berupa : pertukaran mahasiswa, melakukan magang/praktik kerja, melakukan proyek penelitian/riset, mengajar disatuan pendidikan, melakukan kegiatan wirausaha, membuat studi/proyek independen, dan melaksanakan proyek pengabdian kepada masyarakat di desa. Semua kegiatan tersebut harus dilaksanakan dengan bimbingan dari dosen.

Mata kuliah adalah istilah lain yang memiliki arti mata pelajaran. Mata kuliah ini dipergunakan untuk para pelajar yang menyandang sebagai mahasiswa atau mahasiswi di perguruan tinggi di Indonesia. Di dalam perguruan tinggi, mata kuliah terbagi menjadi dua bagian, yaitu : mata kuliah wajib, dan mata kuliah pilihan. Mata kuliah wajib merupakan mata kuliah yang harus di ikuti oleh para mahasiswa dan mahasiswi sesuai dengan Kartu Rencana Studi (KRS) yang telah ditentukan setiap semester oleh perguruan tinggi, sedangkan mata kuliah pilihan merupakan mata kuliah yang dipilih berdasarkan kebutuhan atau keinginan mahasiswa dan mahasiswi. Sistem pendukung keputusan merupakan sebuah sistem yang dapat membantu untuk memecahkan masalah maupun kemampuan komunikasi[2]. Sistem ini digunakan untuk membantu pengambilan keputusan dalam sebuah masalah yang tidak seorang pun tahu secara pasti bagaimana keputusan seharusnya dibuat. Sistem Pendukung Keputusan bertujuan untuk menyediakan informasi terkait pengambilan keputusan, memberikan hasil keputusan serta mengarahkan kepada pengguna informasi agar dapat melakukan pengambilan keputusan dengan lebih baik[3]. Sistem ini juga merupakan salah satu bagian dari ilmu komputer yang bertujuan mengambil keputusan dalam memanfaatkan data dan model tertentu, 
untuk memecahkan berbagai persoalan. Terdapat beberapa model atau metode yang dapat digunakan dalam subsistem manajamen model, seperti Topsis, AHP, SAW, Smart, WP, Sistem Pakar, dan masih banyak lagi. Namun yang saya gunakan pada penelitian ini adalah Smart[4].

SMART yang sering disebut dengan (Simple Multi Attribute Rating Technique) adalah salah satu algoritma yang digunakan untuk pengambilan keputusan. Algoritma Smart juga dikenal dengan algoritma dengan teknik pembuatan keputusan[5], [6]. Metode ini membutuhkan beberapa alternatif. Setiap pembuat keputusan harus memilih sebuah alternatif yang sesuai dengan tujuan yang telah dirumuskan. Setiap alternatif terdiri dari sekumpulan atribut dan setiap atribut mempunyai nilai-nilai. Nilai ini dirata-rata dengan skala tertentu. Oleh karena itu penulis melakukan penelitian ini untuk menentukan mata kuliah terfavorit menggunakan metode SMART untuk menentukan perangkingan prioritas. Dengan menggunakan metode tersebut akan dihasilkan keputusan yang dapat menjadi pertimbangan dalam menentukan mata kuliah terfavorit pada Kampus Merdeka di STIKOM Tunas Bangsa. Berdasarkan hal diatas, maka penulis mengangkat judul "Penerapan Metode SMART Dalam Menentukan Mata Kuliah Terfavorit Pada Kampus Merdeka Di STIKOM Tunas Bangsa (Studi Kasus Prodi Sistem Informasi dan Teknik Informatika Di STIKOM Tunas Bangsa)"[7].

\section{METODOLOGI PENELITIAN}

Metode penelitian merupakan langkah yang dimililki dan dilakukan oleh peneliti dalam rangka unutk mengumpulkan informasi atau data serta melakukan investigasi pada data yang telah didapatkan. Adapun metode penyelesaian yang digunakan dalam penelitian ini yaitu metode Sistem Pendukung Keputsan dengan Algoritma SMART (Simple Multi Aattribute Rating Technique)[8].

\subsection{Prosedur Pengumpulan Data}

Dalam melakukan penelitian untuk mendapatkan data dan informasi, maka metode yang digunakan dalam proses pengumpulan data sebagai berikut :

a) Metode Literatur

Metode literature merupakan metode yang menggunakan teknik pengumpulan data terhadap buku-buku, catatan-catatan dan laporan yang berhubungan dengan penelitian ini.

b) Metode Angket (Kuesioner)

Kuesioner merupakan metode pengumpulan data yang dilakukan dengan mengajukan beberapa pertanyaan dan pernyataan kepada responden agar dijawab.

Berdasarkan bentuk pertanyaannya, kuesioner dapat dikategorikan dalam dua jenis, yakni kuesioner terbuka dan tertutup.

\subsection{Analisis Data}

Dalam mengolah data menjadi sebuah informasi baru diperlukan analisa data agar data tersebut mudah dipahami dan bermanfaat dalam menentukan mata kuliah terfavorit. Data yang diperoleh dalam penelitian ini yaitu dengan mengguakan kuesioner.

a) Alat Analisis Data

Alat yang digunakan pada penelitian ini terlebih dahulu diperoses menggunakan Microsoft excel kemudian data diolah menggunakan SPSS. Kemudian untuk melakukan pengujian data, menggunakan aplikasi offline yang sudah disiapkan.

b) Instrumen Penelitian

Adapun instrumen yang digunakan dalam penelitian ini yaitu :

1) Perangkat keras

Perangkat keras yang digunakan dalam penelitian ini yaitu :

a. Processor Intel(R) Core ${ }^{\mathrm{TM}} \mathrm{i5}-4310 \mathrm{U}$ CPU @ 2.00Ghz 2.60 Ghz

b. RAM 4GB

c. Mainboard Intel Celeron

d. Mouse

e. Smartphone

2) Perangkat Lunak
a. Bahasa Sistem Operasi Windows 1064 bit
b. Microsoft Word
c. Microsoft Excel
d. $M y S Q L$
e. $X A M P P$
f. $S P S S$

c) Diagram Aktifitas Kerja Penelitian

Berikut ini alur kerja yang akan dilakukan pada penelitian ini yang digambarkan dalam diagram berikut. 


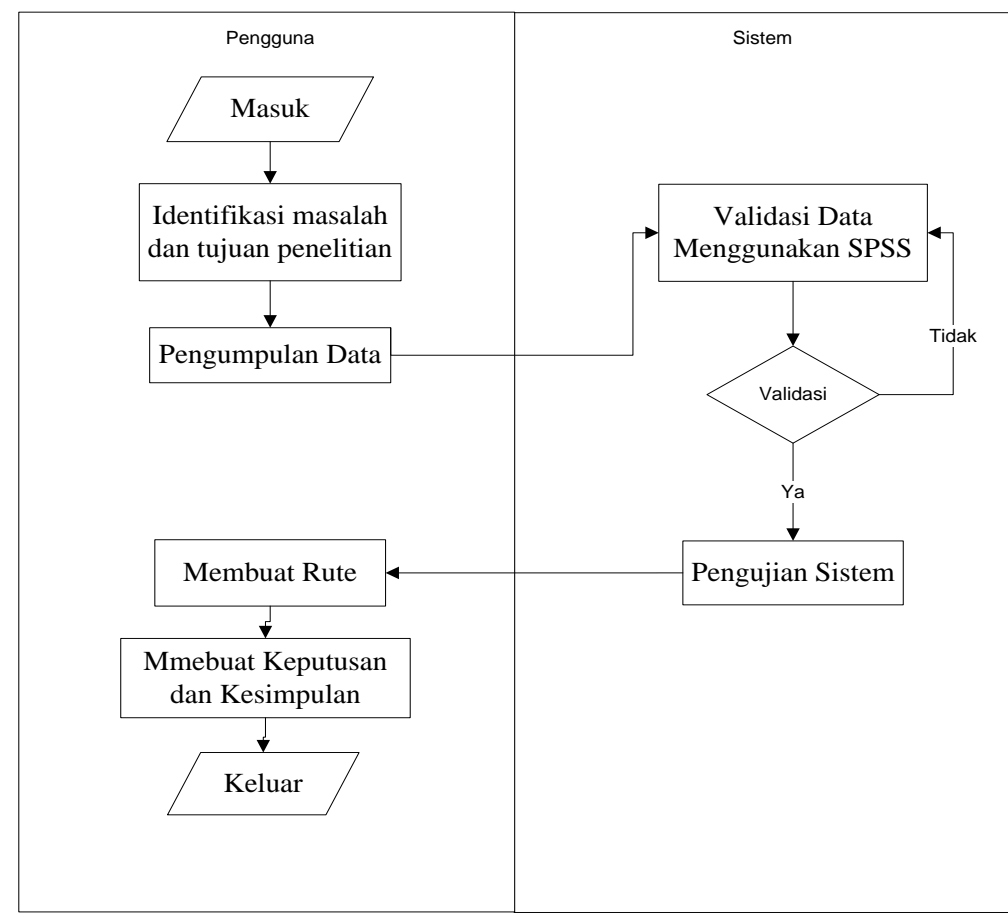

Gambar 1. Activity Diagram Penelitian

Gambar 1 menjelaskan penulis atau pengguna mengindentifikasi masalah dan tujuan penelitian yang dilakukan, mengumpulkan data berupa kuesioner yang diberikan, pada aplikasi SPSS.

d) Pemodelan Metode

Metode yang digunakan dalam penelitian ini adalah SMART. Dalam pemodelan ini dilakukan pada sampel dari data set, kemudian menentukan jumlah kriteria, setelah jumlah kriteria ditemukan kemudian memberikan nilai 0-100 berdasarkan prioritas dengan melakukan normalisasi agar dapat memberikan nilai kriteria untuk setiap alternatif. Selanjutnya menghitung nilai Utility untuk setiap kriteria yang akan dijadikan tolak ukur penyelesaian masalah, setelah itu menghitung nilai akhir, maka dapat melakukan perangkingan[9].

\section{ANALISA DAN PEMBAHASAN}

Data berikut adalah data yang diambil dari hasil kuisioner yang dibagikan kepada mahasiswa dan mahasiswi STIKOM Tunas Bangsa yang dilakukan lebih dari satu minggu untuk mengumpulkan kuisioner yang memenuhi sebagian dari populasi. Data Berikut berupa data mata kuliah, satuan kredit semester (SKS), rata-rata alasan, ratarata peluang.

\subsection{Pengelolaan Data}

Penulis melakukan penelitian ini untuk menentukan mata kuliah terfavorit menggunakan metode SMART. Dengan menggunakan metode tersebut akan dihasilkan keputusan yang dapat menjadi pertimbangan dalam menentukan mata kuliah pada kampus merdeka. Berdasarkan hal diatas, perhitungan yang akan dilakukan dengan menggunakan metode SMART[10]. Berikut adalah perhitungan manual dengan menggunakan metode SMART, yaitu :

1) Menentukan jumlah kriteria dari keputusan yang akan di ambil.

Berikut adalah data yang diambil dari STIKOM Tunas Bangsa Pematangsiantar yang diambil selama satu bulan lebih, data berikut berupa kriteria dalam menentukan mata kuliah terfavorit pada kampus merdeka di STIKOM Tunas Bangsa Pematangsiantar. Data tersebut bisa dilihat pada tabel berikut :

Tabel 1. Data Penelitian Terhadap Mata Kuliah Pada Kampus Merdeka di STIKOM Tunas Bangsa

\begin{tabular}{llrrrr}
\hline \multirow{2}{*}{ No. Matakuliah } & & Kumlah yang milih & SKS & Alasan & Peluang Kerja \\
\hline 1 & Basis Data II (2 Sks) & 3 & 2 & 2 & 3 \\
2 & Administrasi Jaringan (2 Sks) & 16 & 2 & 3.4 & 5 \\
3 & Aljabar Linier (2 Sks) & 19 & 2 & 2.727 & 3.778 \\
4 & Analisis Big Data (3 Sks) & 12 & 3 & 5 & 4.167 \\
5 & Analisis Dan Perancangan Sistem (2 Sks) & 11 & 2 & 3.75 & 3.909 \\
6 & Arsitektur dan Organisasi Komputer (3 Sks) & 9 & 3 & 3.25 & 4 \\
7 & Bahasa Inggris II (2 Sks) & 29 & 2 & 3.267 & 4 \\
8 & Bahasa Inggris III (2 Sks) & 28 & 2 & 2.538 & 3.636 \\
9 & Bahasa Inggris IV (2 Sks) & 24 & 2 & 2.857 & 3.5 \\
\hline
\end{tabular}




\begin{tabular}{rlrrrr}
\hline No. & \multicolumn{1}{c}{ Matakuliah } & \multicolumn{3}{c}{ Kriteria } \\
& & Jumlah yang milih & SKS & Alasan & Peluang Kerja \\
\hline 10 & Bahasa Inggris V (2 Sks) & 16 & 2 & 3.25 & 4 \\
11 & Bahasa Inggris Vi (2 Sks) & 23 & 2 & 3.6 & 3 \\
12 & Bahasa Inggris VII (2 Sks) & 19 & 2 & 4 & 5 \\
13 & Bahasa Pemrograman I (2 Sks) & 8 & 2 & 4.5 & 4.25 \\
14 & E-Commerce (3 Sks) & 3 & 8 & 4 & 4.125 \\
15 & Pemrograman Web I (2 Sks) & 59 & 2 & 2.882 & 4.111 \\
\hline
\end{tabular}

2) Sistem secara default memberikan nilai 0-100 berdasarkan prioritas dengan melakukan normalisasi $\left(\mathrm{Wj} / \sum \mathrm{Wj}\right)$. Penilaian diatas sudah berdasarkan nilai kriteria seperti pada table berikut.

Tabel 2. Penilaian Bobot Kriteria

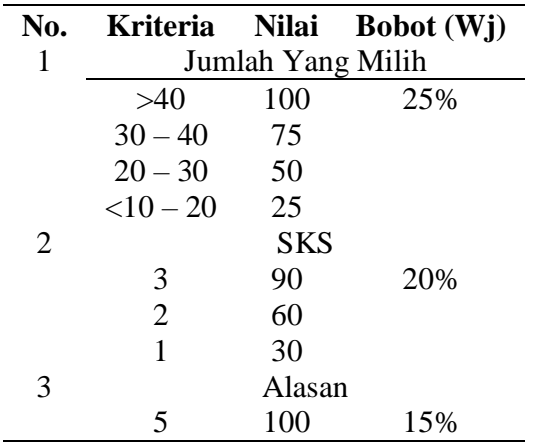

\begin{tabular}{cccc}
\hline & 4 & 80 & \\
& 3 & 60 & \\
& 2 & 40 & \\
& 1 & 20 & \\
No. & Kriteria & Nilai & Bobot (Wj) \\
4 & \multicolumn{3}{c}{ Peluang Kerja } \\
& 5 & 100 & $40 \%$ \\
& 4 & 80 & \\
& 3 & 60 & \\
& 2 & 40 & \\
& 1 & 20 & \\
\end{tabular}

3) Memberikan nilai kriteria untuk setiap alternative

Dapatlah hasil penilaian responden menurut kriteria sebagai berikut.

Tabel 3. Penilaian Responden Menurut Kriteria

\begin{tabular}{clrrrr}
\hline \multirow{2}{*}{ No. Matakuliah } & & \multicolumn{2}{c}{ Kriteria } \\
& & Jumlah Yang Dipilih & SKS & Alasan & Peluang Kerja \\
\hline 1 & Basis Data II (2 Sks) & 25 & 60 & 25 & 50 \\
2 & Administrasi Jaringan (2 Sks) & 25 & 60 & 75 & 100 \\
3 & Aljabar Linier (2 Sks) & 25 & 60 & 50 & 75 \\
4 & Analisis Big Data (3 Sks) & 25 & 90 & 100 & 100 \\
5 & Analisis Dan Perancangan Sistem (2 Sks) & 25 & 60 & 75 & 75 \\
6 & Arsitektur dan Organisasi Komputer (3 Sks) & 25 & 90 & 75 & 75 \\
7 & Bahasa Inggris II (2 Sks) & 50 & 60 & 75 & 75 \\
8 & Bahasa Inggris III (2 Sks) & 50 & 60 & 50 & 75 \\
9 & Bahasa Inggris IV (2 Sks) & 50 & 60 & 50 & 75 \\
10 & Bahasa Inggris V (2 Sks) & 25 & 60 & 75 & 75 \\
11 & Bahasa Inggris Vi (2 Sks) & 50 & 60 & 75 & 50 \\
12 & Bahasa Inggris VII (2 Sks) & 25 & 60 & 75 & 100 \\
13 & Bahasa Pemrograman I (2 Sks) & 25 & 60 & 100 & 100 \\
14 & E-Commerce (3 Sks) & 25 & 90 & 75 & 100 \\
15 & Pemrograman Web I (2 Sks) & 100 & 60 & 50 & 100 \\
\hline
\end{tabular}

4) Menghitung nilai Utility untuk setiap kriteria masing-masing.

Maka berikut ini perhitungan nilai utility Ui (ai) $=100($ Cmax - Cout $i) /($ Cmax - Cmin $) \%$ yaitu sebagai berikut :

Tabel 4. Nilai Utility Terhadap Alternatif

\begin{tabular}{|c|c|c|c|c|c|}
\hline \multirow[t]{2}{*}{ No. } & \multirow[t]{2}{*}{ Matakuliah } & \multicolumn{4}{|c|}{ Kriteria } \\
\hline & & Jumlah Yang Milih & SKS & Alasan & Peluang Kerja \\
\hline 1 & Basis Data II (2 Sks) & 75 & 40 & 75 & 50 \\
\hline 2 & Administrasi Jaringan (2 Sks) & 75 & 40 & 25 & 0 \\
\hline 3 & Aljabar Linier (2 Sks) & 75 & 40 & 50 & 25 \\
\hline 4 & Analisis Big Data (3 Sks) & 75 & 10 & 0 & 0 \\
\hline 5 & Analisis Dan Perancangan Sistem (2 Sks) & 75 & 40 & 25 & 25 \\
\hline 6 & Arsitektur dan Organisasi Komputer (3 Sks) & 75 & 10 & 25 & 25 \\
\hline 7 & Bahasa Inggris II (2 Sks) & 50 & 40 & 25 & 25 \\
\hline 8 & Bahasa Inggris III (2 Sks) & 50 & 40 & 50 & 25 \\
\hline 9 & Bahasa Inggris IV (2 Sks) & 50 & 40 & 50 & 25 \\
\hline 10 & Bahasa Inggris V (2 Sks) & 75 & 40 & 25 & 25 \\
\hline 11 & Bahasa Inggris Vi (2 Sks) & 50 & 40 & 25 & 50 \\
\hline 12 & Bahasa Inggris VII (2 Sks) & 75 & 40 & 25 & 0 \\
\hline 13 & Bahasa Pemrograman I (2 Sks) & 75 & 40 & 0 & 0 \\
\hline 14 & E-Commerce (3 Sks) & 75 & 10 & 25 & 0 \\
\hline
\end{tabular}




\begin{tabular}{|c|c|c|c|c|c|}
\hline \multirow[t]{2}{*}{ No. } & \multirow[t]{2}{*}{ Matakuliah } & \multicolumn{4}{|c|}{ Kriteria } \\
\hline & & Jumlah Yang Milih & SKS & Alasan & Peluang Kerja \\
\hline 15 & Pemrograman Web I (2 Sks) & 0 & 40 & 50 & 0 \\
\hline
\end{tabular}

Kemudian menghitung keseluruhan Utility nilai $\mathrm{U}(\mathrm{ai})=\sum m J=1 \mathrm{Wj} * U i(\mathrm{ai})$. Berikut ini adalah tabelnya yaitu :

Tabel 5. Nilai Keseluruhan Utility Terhadap Alternatif

\begin{tabular}{|c|c|c|c|c|c|}
\hline \multirow[t]{2}{*}{ No. } & \multirow[t]{2}{*}{ Matakuliah } & \multicolumn{4}{|c|}{ Kriteria } \\
\hline & & Jumlah Yang Dipilih & SKS & Alasan & Peluang Kerja \\
\hline 1 & Basis Data II (2 Sks) & 18.75 & 8 & 11.25 & 20 \\
\hline 2 & Administrasi Jaringan (2 Sks) & 18.75 & 8 & 3.75 & 0 \\
\hline 3 & Aljabar Linier (2 Sks) & 18.75 & 8 & 7.5 & 10 \\
\hline 4 & Analisis Big Data (3 Sks) & 18.75 & 2 & 0 & 0 \\
\hline 5 & Analisis Dan Perancangan Sistem (2 Sks) & 18.75 & 8 & 3.75 & 10 \\
\hline 6 & Arsitektur dan Organisasi Komputer (3 Sks) & 18.75 & 2 & 3.75 & 10 \\
\hline 7 & Bahasa Inggris II (2 Sks) & 12.5 & 8 & 3.75 & 10 \\
\hline 8 & Bahasa Inggris III (2 Sks) & 12.5 & 8 & 7.5 & 10 \\
\hline 9 & Bahasa Inggris IV (2 Sks) & 12.5 & 8 & 7.5 & 10 \\
\hline 10 & Bahasa Inggris V (2 Sks) & 18.75 & 8 & 3.75 & 10 \\
\hline 11 & Bahasa Inggris Vi (2 Sks) & 12.5 & 8 & 3.75 & 20 \\
\hline 12 & Bahasa Inggris VII (2 Sks) & 18.75 & 8 & 3.75 & 0 \\
\hline 13 & Bahasa Pemrograman I (2 Sks) & 18.75 & 8 & 0 & 0 \\
\hline 14 & E-Commerce (3 Sks) & 18.75 & 2 & 3.75 & 0 \\
\hline 15 & Pemrograman Web I (2 Sks) & 0 & 8 & 7.5 & 0 \\
\hline
\end{tabular}

5) Menghitung nilai akhir dan melakukan Perangkingan

Melihat dari hasil di di atas berikut ini perangkingannya. Adapun sesuai dengan kasus di atas yang dijadikan sebagai prioritas adalah yang memiliki nilai terendah yaitu sebagai berikut:

Tabel 6. Nilai Perangkingan

\begin{tabular}{clcl}
\hline No & \multicolumn{1}{c}{ Hasil Akhir } & Nilai & Keterangan \\
\hline 1 & Basis Data II (2 Sks) & 58 & Peringkat 1 \\
2 & Aljabar Linier (2 Sks) & 44.25 & Peringkat 2 \\
3 & Bahasa Inggris Vi (2 Sks) & 44.25 & Peringkat 3 \\
4 & Analisis Dan Perancangan Sistem (2 Sks) & 40.5 & Peringkat 4 \\
5 & Bahasa Inggris V (2 Sks) & 40.5 & Peringkat 5 \\
6 & Bahasa Inggris III (2 Sks) & 38 & Peringkat 6 \\
7 & Bahasa Inggris IV (2 Sks) & 38 & Peringkat 7 \\
8 & Arsitektur dan Organisasi Komputer (3 Sks) & 34.5 & Peringkat 8 \\
9 & Bahasa Inggris II (2 Sks) & 34.25 & Peringkat 9 \\
10 & Administrasi Jaringan (2 Sks) & 30.5 & Peringkat 10 \\
11 & Bahasa Inggris VII (2 Sks) & 30.5 & Peringkat 11 \\
12 & Bahasa Pemrograman I (2 Sks) & 26.75 & Peringkat 12 \\
13 & E-Commerce (3 Sks) & 24.5 & Peringkat 13 \\
14 & Analisis Big Data (3 Sks) & 20.75 & Peringkat 14 \\
15 & Pemrograman Web I (2 Sks) & 15.5 & Peringkat 15 \\
\hline
\end{tabular}

Maka didapatlah hasil dari metode SMART dapat menentukan mata kuliah yang banyak diminati mahasiswa Kampus Merdeka ialah Alternatif Basis Data II dengan nilai 58.

\subsection{Pembahasan}

Berdasarkan perhitungan diatas dapatlah hasil dari tujuan penelitian ini yang menyatakan bahwa menentukan mata kuliah terfavorit pada Kampus Merdeka di STIKOM Tunas Bangsa dengan menggunakan metode SMART berjalan sangat baik. Dari hasil perhitungan manual dapatlah nilai terendah adalah 15,5 dengan tingkat kecocokan pada program sistem pendukung keputusan menentukan mata kuliah terfavorit adalah Bahasa Inggris I. Maka tercapailah tujuan penelitian ini dalam menentukan mata kuliah terfavorit pada Kampus Merdeka di STIKOM Tunas Bangsa dengan menggunakan metode SMART. Berikut ini merupakan langkah-langkah penerapan algoritma pada sistem: 
a) Buka sistem

b) Data Kriteria

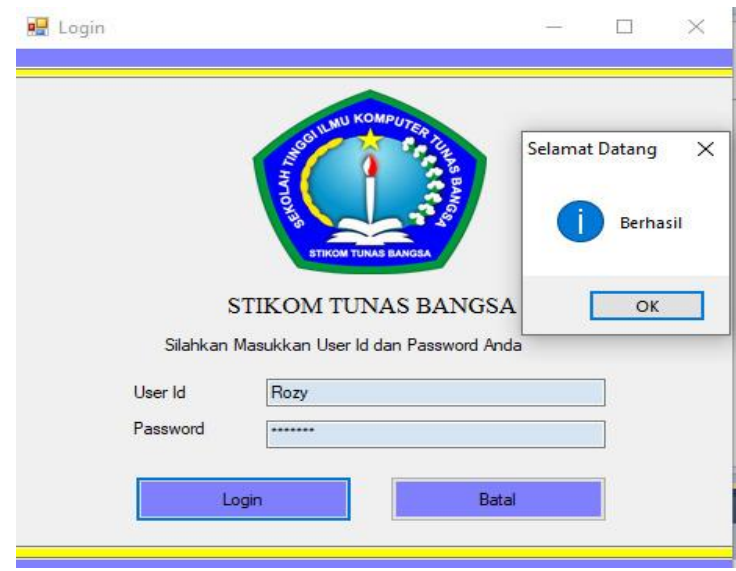

Gambar 2. Tampilan Awal Sistem

喂 Kriteria

Data Kriteria

Kriteria digunakan sebagai data penilaian (yang dinilai) dari setiap Alternatif

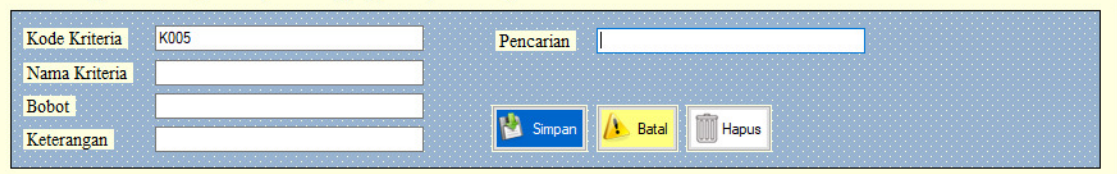

\begin{tabular}{|c|c|c|c|c|}
\hline & $\begin{array}{c}\text { Kode } \\
\text { Kotiteria }\end{array}$ & Nama Kitteria & Bobot & Keterangan \\
\hline \multirow[t]{4}{*}{ • } & K001 & SKS & 0.2 & Satuan Kredit Semester pada Mata Kuliah \\
\hline & K002 & Jumlah yang Dipitih & 0.25 & Jumlah mata kuliah yang dipitih mahasiswa \\
\hline & K003 & Rata-Rata Alasan & 0.15 & Jumlah nilai alasan dibagi dengan jumlah mata kuliah yang dipilih mahasiswa \\
\hline & K004 & Rata-Rata Peluang & 0.4 & Jumlah nilai peluang keja dibagi dengan jumlah mata kuliah yang dipilih mahasiswa \\
\hline - & & & & \\
\hline
\end{tabular}

c) Data Nilai Untuk Setiap Alternatif

Gambar 3. Tampilan Isi Data Kriteria

喂 Nilai

Data Nilai untuk Setiap Alternatif

Berikut data nilai kriteria untuk setiap Alternatif pada periode terpilih

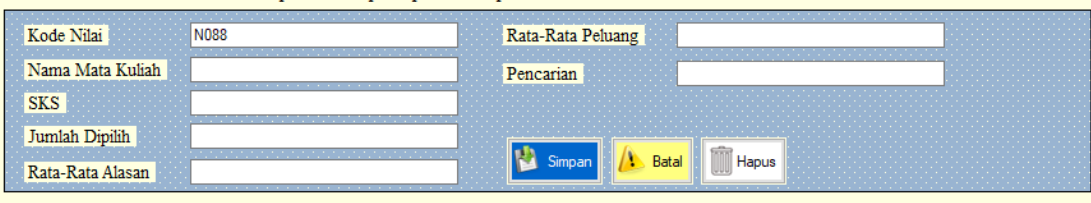

\begin{tabular}{|c|c|c|c|c|c|c|c|}
\hline & $\begin{array}{l}\text { Kode } \\
\text { Nilai }\end{array}$ & Nama Mata Kuliah & SKS & Jumlah Dipilih & $\begin{array}{l}\text { Rata-Rata } \\
\text { Alasan }\end{array}$ & $\begin{array}{l}\text { Rata-Rata } \\
\text { Peluang }\end{array}$ & $\wedge$ \\
\hline \multirow[t]{15}{*}{ D } & N001 & Administrasi Janingan (2 Sks) & 2 & 16 & 3.4 & 5 & \\
\hline & N002 & Aljabar Linier (2 Sks) & 2 & 19 & 2.727 & 3.778 & \\
\hline & N003 & Analisis Big Data (3 Sks) & 3 & 12 & 5 & 4.167 & \\
\hline & N004 & Analisis Dan Perancangan Sistem (2 Sks) & 2 & 11 & 3.75 & 3.909 & \\
\hline & N005 & Analisis dan Perancangan Sistem Informasi (2 Sks) & 2 & 12 & 2.5 & 3.917 & \\
\hline & N006 & Arsitektur dan Organisasi Komputer (3 Sks) & 3 & 9 & 3.25 & 4 & \\
\hline & N007 & Bahasa Inggis I| (2 Sks) & 2 & 29 & 3.267 & 4 & \\
\hline & N008 & Bahasa Inggris III (2 Sks) & 2 & 28 & 2.538 & 3.636 & \\
\hline & N009 & Bahasa Inggris IV (2 Sks) & 2 & 24 & 2,857 & 3.5 & \\
\hline & N010 & Bahasa Inggris V (2 Sks) & 2 & 16 & 3.25 & 4 & \\
\hline & N011 & Bahasa Inggris Vi (2 Sks) & 2 & 23 & 3.6 & 3 & \\
\hline & N012 & Bahasa Inggis VII (2 Sks) & 2 & 19 & 4 & 5 & \\
\hline & N013 & Bahasa Pemrograman I (2 Sks) & 2 & 8 & 4.5 & 4.25 & \\
\hline & N014 & Bahasa Pemrograman II (2 Sks) & 2 & 8 & 2.125 & 3.75 & \\
\hline & N015 & Basis Data I (3 Sks) & 3 & 3 & 2.333 & 4.333 & $\checkmark$ \\
\hline
\end{tabular}

Gambar 4. Tampilan Data Nilai Untuk Setiap Alternatif 
d) Nilai Alternatif Terhadap Kriteria

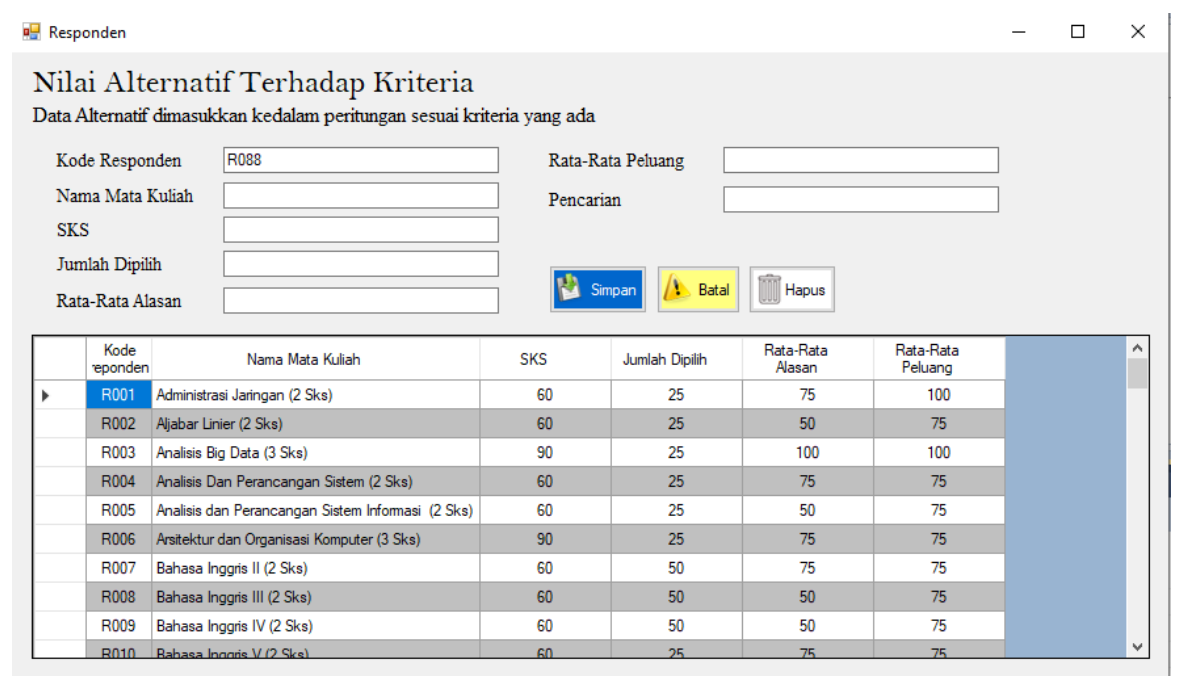

Gambar 5. Tampilan Nilai Alternatif Terhadap Kriteria

e) Nilai Utility

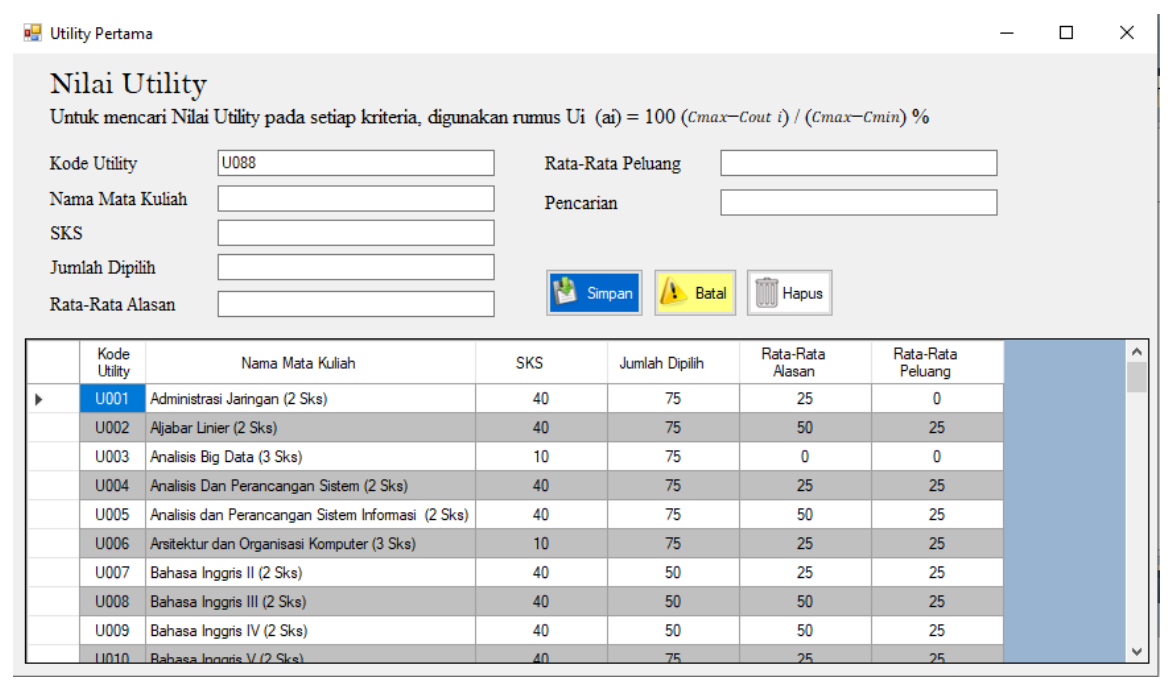

Gambar 6. Tampilan Nilai Utility

f) Nilai Keseluruhan Utility

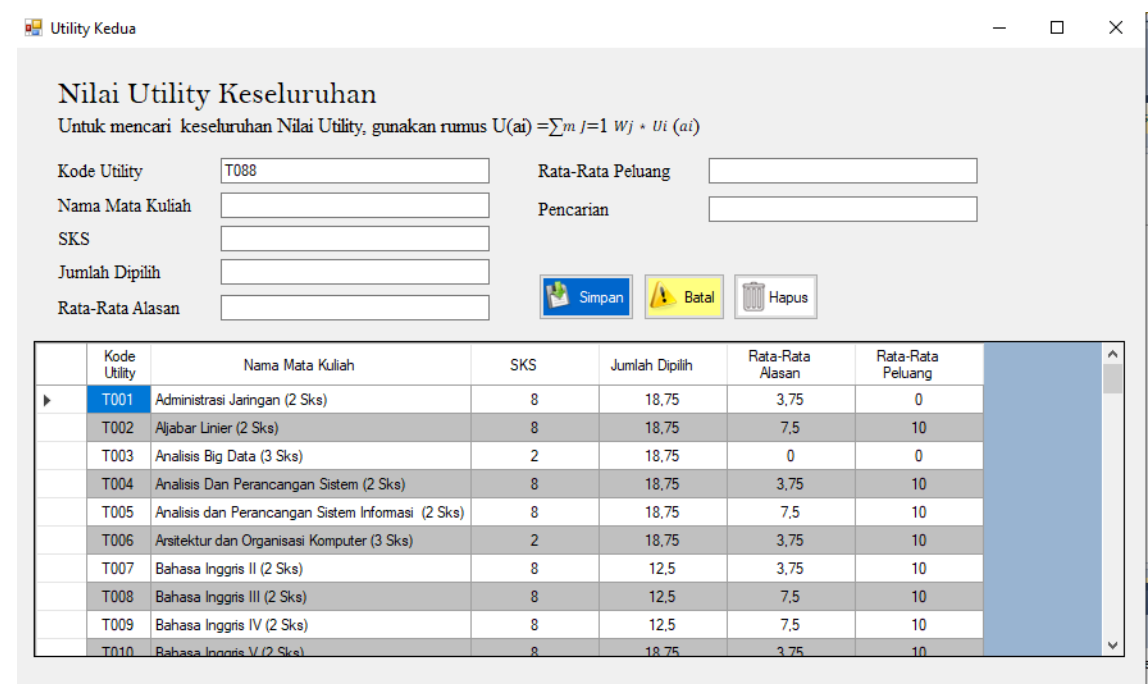

Gambar 7. Tampilan Nilai Keseluruhan Utility 
g) Hasil Akhir

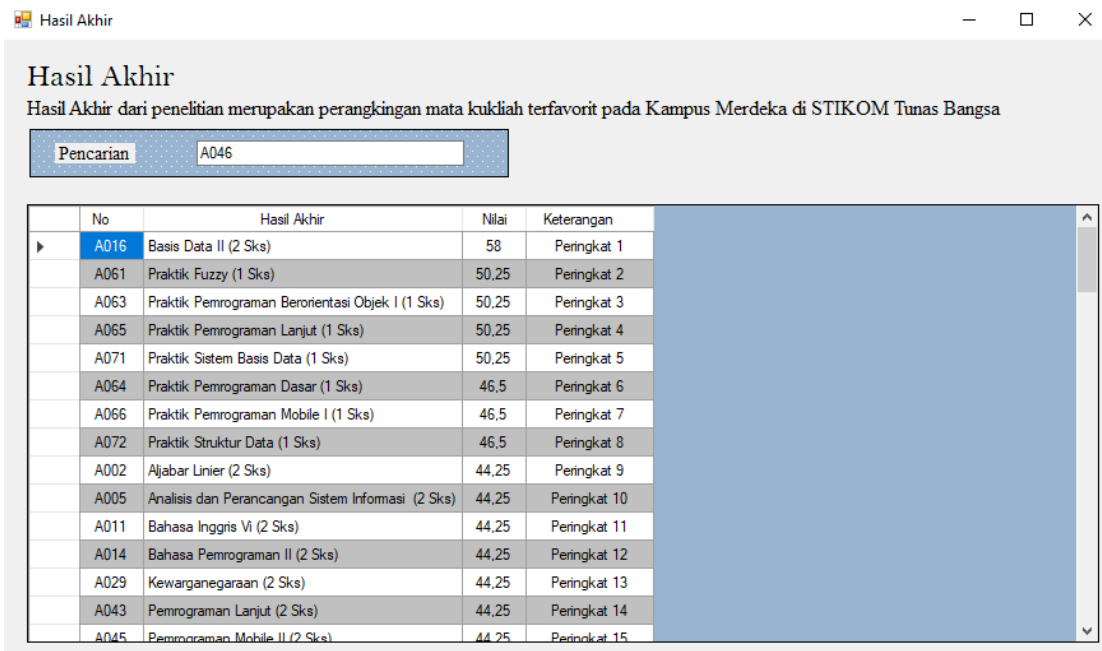

Gambar 8. Tampilan Hasil Akhir

\section{KESIMPULAN}

Berdasarkan hasil tahapan pembahasan yang dilakukan menggunakan metode SMART pada media pembelajaran online dapat disimpulkan sebagai berikut :

a) Dengan adanya metode SMART sebagai proses perhitungan dalam menentukan mata kuliah yang banyak diminati mahasiswa Kampus Merdeka di STIKOM Tunas Bangsa Pematangsiantar berjalan sangat baik.

b) Dari hasil perhitungan manual dan progam yang sudah berjalan maka didapatlah nilai tertingginya adalah 58 diketahui bahwa tingkat kecocokan pada sistem pendukung keputusan menentukan media mata kuliah yang banyak diminati mahasiswa adalah Basis Data II, dan juga didapatkan nilai terendahnya adalah 15,5 pada matakuliah Pemrogramana Web I.

\section{REFERENCES}

[1] I. M. A. Sentosa, "Perancangan Sistem Pendukung Keputusan Pemilihan Sekolah PAUD Menggunakan Metode Smart," Konf. Nas. Sist. Inform. 2017, pp. 446-451, 2017.

[2] A. P. W. alkhairi putrama, "Analisis dalam menentukan produk bri syariah terbaik berdasarkan dana pihak ketiga menggunakan ahp,” vol. 3, no. 1, pp. 60-64, 2018.

[3] P. Alkhairi, A. P. Windarto, and H. S. Tambunan, "Analisis Menentukan Daerah Potensi Terbaik dalam Pengembangan Wilayah Sektor Unggulan Pertanian Menggunakan Metode AHP,” pp. 403-408, 2018.

[4] P. Status, K. Bayi, B. Lahir, D. I. Rumah, D. I. Rumah, and S. Bhayangkara, "Penerapan metode smart (simple multi attribute rating technique) dan algoritma k-nn (k-nearest neighbor) dalam penentuan status kesehatan bayi baru lahir di rumah sakit bhaya....," no. September, 2018, doi: 10.5281/zenodo.1410065.

[5] D. P. Larasati, M. Nasrun, S. Si, and U. A. Ahmad, "Analisis Dan Implementasi Algoritma Fp-Growth Pada Aplikasi Smart Untuk Menentukan Market Basket Analysis Pada Usaha Retail (Studi Kasus : Pt . X )” vol. 2, no. 1, pp. 749-755, 2015.

[6] K. T. Jawa, K. Kunci, and S. Potong, "Pemilihan Jenis Sapi bagi Peternak Sapi Potong dengan Metode SMART," vol. 6341, no. April, 2019.

[7] W. D. Suryono and R. Saptono, "Implementasi Pengembangan Smart Helpdesk di UPT TIK UNS Menggunakan Algoritma Naive Bayes Classifier,” pp. 39-43, 2017.

[8] D. Novianti, I. F. Astuti, and D. M. Khairina, "Sistem Pendukung Keputusan Berbasis Web Untuk Pemilihan Café Menggunakan Metode Smart (Simple Multi-Attribute Rating Technique) (Studi Kasus: Kota Samarinda)," 2016.

[9] J. Rekursif, N. Sesnika, D. Andreswari, and R. Efendi, “Aplikasi Sistem Pendukung Keputusan Pemilihan Gedung Serba Guna Di Kota Bengkulu Dengan Menggunakan Metode Smart Berbasis Android,” vol. 4, no. 1, 2016.

[10] N. H. Dimas Dandy Aryarajendra Suprapto, Fauziah, Iskandar Fitri, "Pengembangan Aplikasi Sistem Informasi Smart Register Online Berbasis Android Menggunakan Algoritma BruteForce,” vol. 4, no. 1, pp. 47-56, 2020, doi: 10.29408/edumatic.v4i1.2106. 